\title{
A POSSIBLE CASE OF SUPERFETATION IN MAN
}

\author{
J. B. SCRIMGEOUR AND T. G. BAKER
}

Department of Obstetrics and Gynaecology, University of Edinburgh, Edinburgh EH3 $9 E \mathrm{~W}$

\section{(Received 5th Fanuary 1973)}

\begin{abstract}
Summary. A case is described of human dizygous twins showing marked differences in size, embryological development and presumed age. By definition, this is a case of 'superfetation' although the mechanism whereby it occurs remains unknown. The possible mechanisms (fertilization of a second ovum during pregnancy; embryonic diapause resulting from delayed implantation; and retarded growth) are discussed.
\end{abstract}

\section{INTRODUCTION}

Superfetation may be defined as the development of fertilized ova in a uterus which already contains the products of conception from a previous reproductive cycle. The subject has been well reviewed by Radash (1921), Studdiford (1936) and Deanesly (1966). If such a conception is possible in humans, the simplest explanation would be that ovulation had taken place during the initial pregnancy, the uterine cavity had permitted the passage of spermatozoa and the second fertilized ovum had managed to implant in the uterus adjacent to the first. Alternatively, both embryos could have been fertilized at the same time although one subsequently showed delayed implantation or retarded development.

\section{MATERIALS AND METHODS}

The patient, Miss S.P., aged 20 years, para $1+1$, was admitted to the Simpson Memorial Maternity Pavilion on 24th June 1972 because of vaginal bleeding of 24-hr duration. Her last menstrual period had started on 12th March 1972 and she was therefore presumed to be about 13 weeks post-conception.

On examination, the uterus was felt to be the size of a 10-week gestation and the cervical os was closed. In spite of sedation and complete bed rest, she aborted twins $24 \mathrm{hr}$ later. The products of conception are described below. Evacuation of the uterus was carried out but no evidence of a congenital uterine malformation was found.

The twins, which were delivered within $15 \mathrm{~min}$ of each other, were photographed both within, and after removal from, their separate amniotic sacs (Pl. 1, Figs 1 and 2). They were examined macroscopically and various measurements made (Table 1). The small embryo (Pl. 1, Fig. 2) was subsequently fixed intact in Bouin's aqueous fluid, embedded in paraffin wax and serially sectioned at $10 \mu \mathrm{m}$ thickness. Various organs from the larger twin were 
also removed and were subjected to the same procedures to assess the degree of autolytic change which had occurred.

Table 1. Measurements and other data for twins ' $A$ ' and ' $B$ '

\begin{tabular}{l|c|c}
\hline \multicolumn{1}{c|}{ Data } & Twin ' $A$ ' & Twin ' $B$ ' \\
\hline Diameter of amniotic sac (cm) & $4 \cdot 2$ & $8 \cdot 5$ \\
Crown-rump length (mm) & $16 \cdot 5$ & $40 \cdot 0$ \\
Heel-toe length (mm) & Not applicable & $6 \cdot 0$ \\
External genitalia & Indifferent & Indifferent \\
Gonads & Genital ridge stage & Ovaries \\
Placental wet-weight (g) & $2 \cdot 96$ & $14 \cdot 65$ \\
Total HCG/placenta* & 868 & 5415 \\
Age post-conception (days) & $(775$ to 874) & $(4715$ to 6308) \\
& 38 & 57 \\
\hline
\end{tabular}

Fetal weight was not measured.

* Estimate of potency with fiducial limits.

\section{RESULTS}

\section{Gross morphology of the twins}

The marked difference in size of the two conceptuses is well shown in Pl. 1, Figs 1 and 2. The smaller sac measured some $4.2 \mathrm{~cm}$ in diameter, while its larger partner was about $8.4 \mathrm{~cm}$. The placentae also differed in size, as did the amount of HCG they contained (Table 1). They were completely separate and showed no evidence of anastomosis between the placentae. Plate 1, Fig. 2 shows the gross appearance of the embryos which were apparently fresh and not autolysed when aborted (but see below). On the basis of the data shown in Table 1, the twins differed in age by about 20 days. Twin ' $A$ ' had well-developed limb buds which showed no signs of differentiation of digits (Pl. 1, Fig. 2). An umbilical hernia characteristic of embryos aged 38 days (Witschi, 1962) was beginning to form and visceral arches could be detected. The development of the eyes was advanced for an embryo of this age since pigmentation of the iris (which normally occurs on about Day 40 ) could be detected.

By contrast, twin ' $B$ ' had fully differentiated limbs, with digits. The eyes, ears and ribs were well developed but the external genitalia were sexually indifferent. On the basis of crown-rump length and development, its age was estimated to be 57 days post-conception.

\section{Histology}

Both twins showed minor autolytic changes although these were slightly

\section{EXPLANATION OF PLATE 1}

Frg. 1. The aborted twins within their amniotic sacs.

Fig. 2. The great disparity in age and embryological stage is clearly shown in this photograph. The smaller twin has undifferentiated limb buds without phalanges and the tail has not regressed. Note pigmentation of eye. 
PL.TIE ।
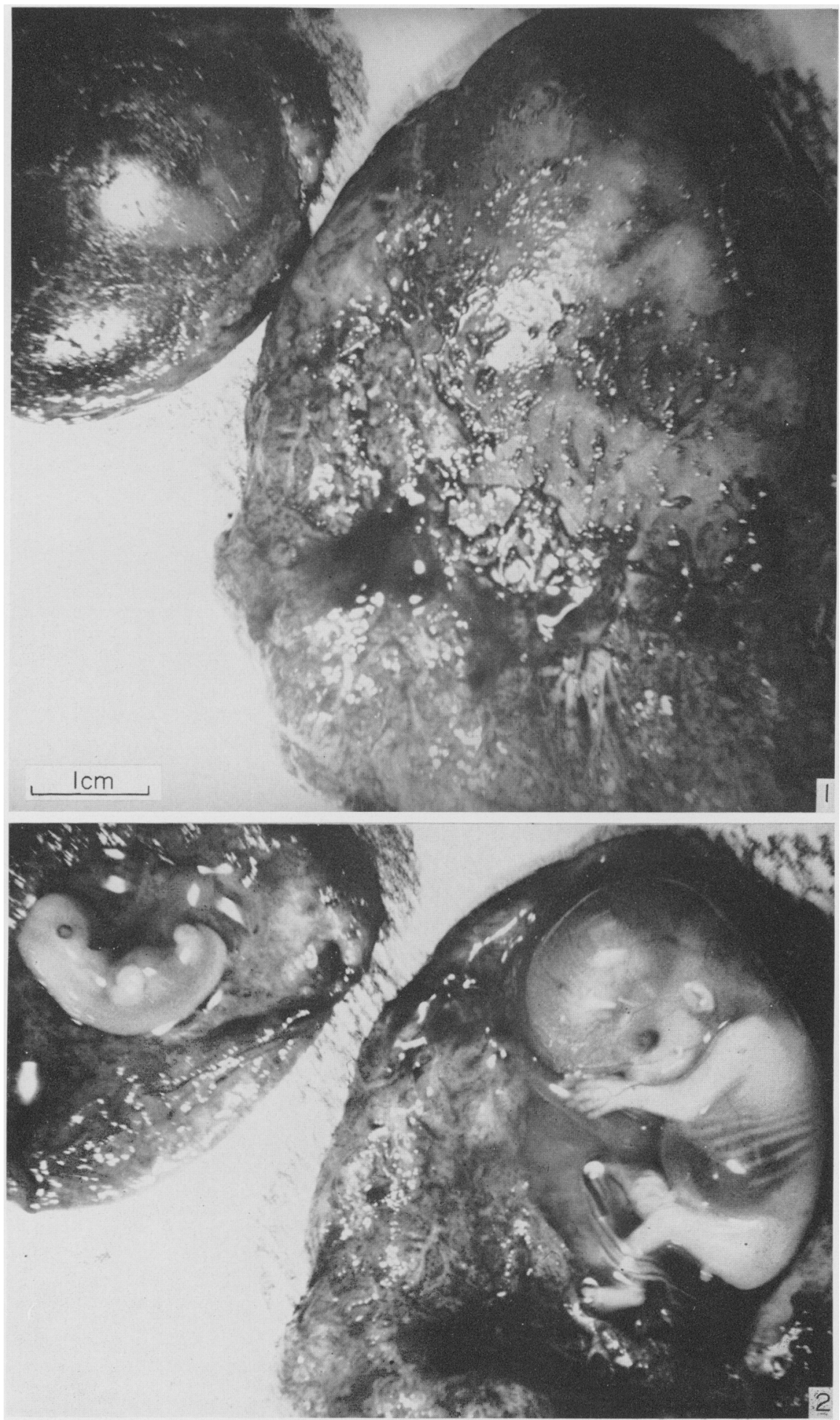

ifining p. 70 
PLATE 2

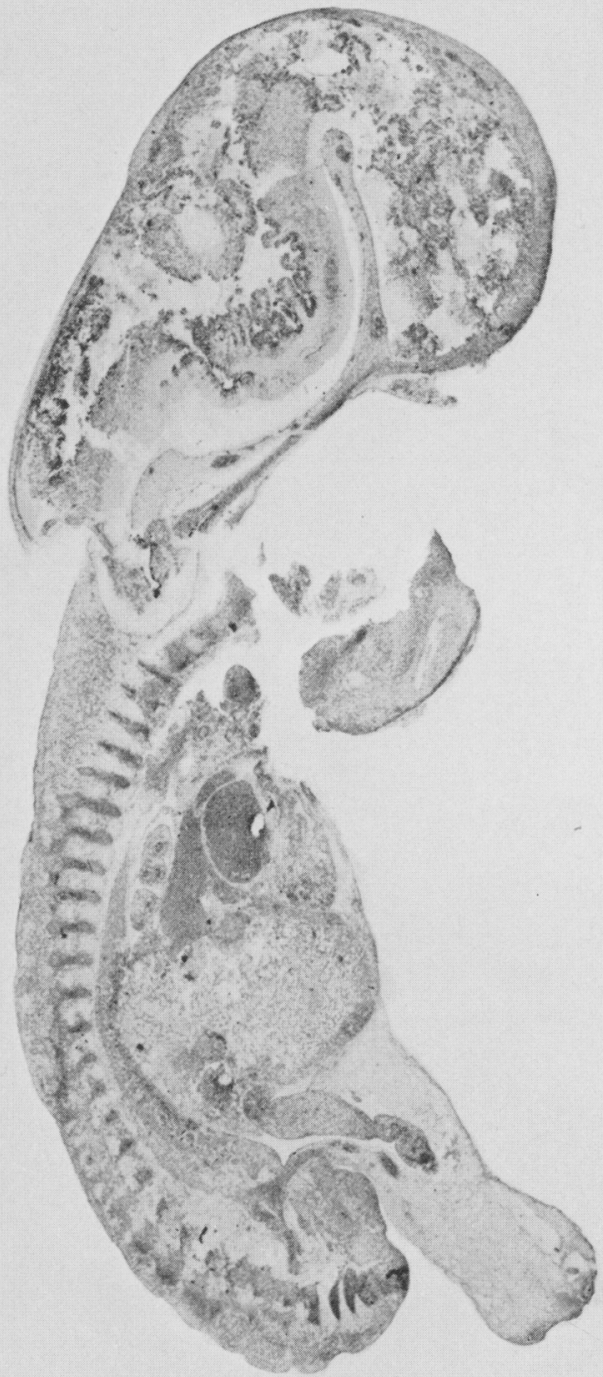

Fig. 3. Sagital section through the small embryo. Apart from the brain, few signs of necrotic changes can be detected. 
more pronounced in the smaller twin 'A' (P1. 2, Fig. 3) which could, therefore, have died a few hours before its larger partner. The gonads of twin ' $B$ ' were clearly differentiated as ovaries, while those of ' $\mathrm{A}$ ' consisted merely of genital ridges containing primordial germ cells (Pl. 2, Fig. 3). Cultures of fetal cells, with a view to chromosomal analysis, were unsuccessful.

\section{DISCUSSION}

It would appear that belief in the occurrence of superfetation has an ancient origin since, according to Radash (1921), the subject was discussed by Hippocrates, Pliny and Aristotle. Numerous attempts to induce superfetation have been largely unsuccessful although sporadic reports deal with its spontaneous occurrence in various species of mammal (e.g. mouse: Littleford \& Gysin, 1944; Rollhauser, 1949; Bloch, 1952; rat: King, 1913; Slonaker, 1934; Weichert, 1942; cat: Markee \& Hinsey, 1935; sheep and pigs: Smith, 1932; Grant, 1934; monkey: Leakey, 1969; see also Deanesly, 1966). In some of these reports, the embryos resulting from one conception time were evidently confined to one uterine horn while those of the second conception were in the other horn.

Superfetation, by its definition, assumes that a number of conditions must prevail before it can occur: (1) ovulation must be possible during a concurrent pregnancy; (2) the Fallopian tubes must be patent during pregnancy, particularly at their internal os, to allow passage of spermatozoa and of the fertilized ovum; (3) the mucus of the cervical canal must allow passage of spermatozoa; and (4) the uterine cavity, already filled to a greater or lesser extent by the first conceptus, must be anatomically and endocrinologically capable of allowing implantation of the second conceptus.

In the human, little is known of ovarian function in early pregnancy. In fourteen specimens studied by Govan $(1968,1970)$, the ovary appeared to be in a state of suspected postovulatory activity until 10 weeks' gestation. Before this, the most striking histological features were large mature Graafian follicles with an average diameter of $8 \mathrm{~mm}$. In most of the follicles, the ovum was degenerate and the nucleus no longer visible. However, 'some retained an ovum of reasonably normal histological appearance' (Govan, 1968). This phenomenon of suspended ovarian activity may be attributable to the high levels of HCG which fall to much lower levels by 11 weeks' gestation. After this age, a renewal of follicular development occurred but less so in the ovary containing the corpus luteum. These new follicles did not exceed $6 \mathrm{~mm}$ in diameter and none appeared to ovulate. On the basis of this evidence, it must be concluded that ovulation in early pregnancy in the human is probably a very rare event, if it occurs at all.

There is no reason to believe that the Fallopian tubes during pregnancy are occluded, but the decidual reaction near the internal os of each tube may be sufficiently marked to oppose the circumference of the os and thus make penetration by spermatozoa more difficult, and that by a fertilized ovum unlikely. Should a fertilized ovum attempt to negotiate the tube in early pregnancy, it seems more likely that an ectopic pregnancy would result 
rather than an intrauterine pregnancy with superfetation. To our knowledge, no case of ectopic pregnancy with concurrent intrauterine pregnancy has been reported in the human.

Until the uterine cavity is obliterated by the fusion of the decidua vera and decidua capsularis, it would be anatomically possible for the second conceptus to be accommodated. There is no evidence, however, to indicate whether such a conceptus would be able to implant on a decidua at the developmental stage of the older conceptus.

In species other than the human, the majority of the pregnancies resulting from one fertilization were evidently confined to one uterine horn while those of the second conception were in the other horn. In comparable reports in women with double uteri, 21-day (Dorgan \& Clarke, 1956) and 56-day intervals between the delivery of fetuses (Williams \& Cummings, 1953) have been reported. In both cases, the discrepancy in size of the fetuses was comparable with the relative time spent in utero. In one reported case, simultaneous abortion occurred (Robinet, Pia \& Ezes, 1970).

In cases where a uterus was either proven to be normally shaped by X-ray or thought to be so on clinical examination, the placenta required to be manually removed (Abrams, 1957; Druker, Finkel \& Savel, 1960) or was noted to be small (Murless \& McLaughlin, 1937; Fontana \& Monif, 1970). This would suggest that the placenta of the second twin was functioning poorly, resulting in a slower rate of growth of its fetus. This may be due to a local uterine abnormality or to local pathology of the placenta. In many cases, this would be expected to result in the death of the smaller twin and the delivery of a fetus papyraceous; alternatively, the smaller twin could result from retarded growth although it would not be expected to show the retarded embryological development found in the present case. If development was monochorionic, a degree of transfusion syndrome may exist to the detriment of the smaller twin. In a review of such cases (fetus papyraceous), Kindred (1944) found ninety-three $(66 \%)$ of 141 cases to be dichorial, indicating that the type of twin placentation is not a critical factor.

Apart from local uterine or placental pathology, another explanation is possible: one twin may delay its own implantation by entering a state of 'embryonic diapause' from which it is later reactivated and only then implants. If both twins are delivered at the same time, there would be a proportionate difference in their size and development. This possibility has been considered in detail in pigs and a similar mechanism may be feasible in other species (Vandeplassche, 1969). Although it would be virtually impossible to prove, it could well explain the occurrence of human superfetation.

\section{ACKNOWLEDGMENTS}

We are grateful to Dr G. D. Matthew, Reader in Obstetrics and Gynaecology, for his permission to publish data relating to his patient, and also to $\mathrm{Dr} \mathrm{B}$. M. Hobson for assays of chorionic gonadotrophin. The expenses incurred in this study were defrayed out of a grant to Dr T. G. Baker by the Population Council, New York. 


\section{REFERENGES}

Abrams, R. H. (1957) Double pregnancy. Report of a case with 35 days between deliveries. Obstet. Gynec., N.Y. 9, 435.

BLoch, S. (1952) Untersuchungen über Superfetation an der Maus. Schweiz. med. Wschr. 82, (i), 632.

DEANESLY, R. (1966) The endocrinology of pregnancy and foetal life. In: Marshall's Physiology of Reproduction, Vol. 3, p. 918. Ed. A. S. Parkes. Longmans, London.

Dorgan, L. T. \& Glarke, P. E. (1956) Uterus didelphys with double pregnancy. Am. 7. Obstet. Gynec. 72, 663.

Druker, P., Finkel, J. \& Savel, L. E. (1960) Sixty-five day interval between the birth of twins. Am. 7. Obstet. Gynec. 80, 761.

Fontana, J. \& Monif, G. R. G. (1970) Superfetation. Obstet. Gynec., N.Y. 35, 585.

Govan, A. D. T. (1968) The human ovary in early pregnancy. F. Endocr. 40, 421.

Govan, A. D. T. (1970) Ovarian follicular activity in late pregnancy. F. Endocr. 48, 235.

Grant, R. (1934) Studies on the reproduction in the ewe. Trans. R. Soc. Edinb. 58, 1.

KindRED, J. E. (1944) Twin pregnancies with one ovum blighted. Report of two cases with comparative study of cases in the literature. Am. F. Obstet. Gynec. 48, 642 .

KING, H. D. (1913) Some anomalies in the gestation of the albino rat Mus norvegicus albinus. Biol. Bull. mar. biol. Lab., Woods Hole. 24, 377.

Leakey, L. S. B. (1969) Presumed superfetation in a monkey. Nature, Lond. 223, 754.

Littleford, R. A. \& Gysin, H. M. (1944) Observations on superfetation in mice. Anat. Rec. 89, 507.

Markee, J. E. \& Hinsey, J. G. (1935) A case of probable superfetation in the cat. Anat. Rec. 61, 241.

Murless, B. G. \& McLaughlin, F. L. (1937) Does superfetation occur? Report of a possible case. Br. med. F. i, 1309.

Radash, H. E. (1921) Superfoetation or superfecundation? Surgery, Gynec., Obstet. 32, 339.

Robinet, G., Pia, G. \& Ezes, H. (1970) Sur un cas de superfoetation. Bull. Féd. Socs Gynéc. Obstét. Lang. fr. 22,451 .

Rollhauser, H. (1949) Superfetation in a mouse. Anat. Rec. 105, 657.

Slonaker, J. R. (1934) Superfetation in the albino rat. Am. F. Physiol. 108, 322.

Smith, A. D. B. (1932) Superfetation: further cases in pigs and sheep. F. Anat., Lond. 62, 100.

StudDiford, W. E. (1936) Is superfetation possible in the human being? Am. F. Obstet. Gynec. 31, 845.

VANDEPLAssche, M. (1969) The physiological explanation of split parturition in the pig and other mammalian species. Annls Endocr. 30, 328.

Weichert, C. K. (1942) A case of parallel embryonic development in the rat and its bearing on the question of superfetation. Anat. Rec. 83, 511 .

Williams, B. \& Gummings, G. (1953) An unusual case of twins. 7. Obstet. Gynec. Br. Commonw. 60, 319.

Witschr, E. (1962) Prenatal vertebrate development. In: Growth; including Reproduction and Morphological Development. Biological Handbooks. Eds. P. L. Altman and D. S. Dittmar. Federation of American Societies for Biology, Washington. 